\title{
PEMANFAATAN LAMPU LISTRIK UNTUK PENINGKATAN HASIL TANGKAPAN PADA BAGAN APUNG TRADISIONAL DI PELABUHAN RATU
}

\section{UTILIZATION OF ELECTRIC LAMPS TO INCREASE CATCH OF TRADITIONAL LIFT NET IN PELABUHAN RATU WATERS}

\author{
Zamdial Ta'alidin *)
}

\begin{abstract}
The objectives of this research were to know the effect of different light sources on the total catch, species composition and size of fish captured by traditional lift net. This research was conducted at the Pelabuhan Ratu Waters, West Java.

Fishing experiment was conducted for 12 hours each night, for 5 night. Fishing operation was conducted alternately for two hours using kerosene lamp and electric lamp.

The light illumination, temperature, salinity and water current were measured after setting the gear, while the catch data were measured after hauling. The maximum light penetration of kerosene lamp was able to reach $9 \mathrm{~m}$ depth (at the center of lift net), $8 \mathrm{~m}$ (at the middle of lift net) and $6 \mathrm{~m}$ (at the corner of lift net). In addition, by using kerosene and electric lamps, the light penetration was able reach $11 \mathrm{~m}$ (at center and midlle of lift net) and $12 \mathrm{~m}$ (at the corner of lift net).
\end{abstract}

The total catch of lift net using kerosene lamp was $85.12 \mathrm{~kg}$ (9,086 fishes) comprise of 12 spesies with sizes $5.3-42.7 \mathrm{~cm}$, while the total catch using combination of kerosene and electric lamps was $148.67 \mathrm{~kg}$ (12,685 fishes) comprise of 18 spesies with sizes $5.95-52.78$ $\mathrm{cm}$.

The results showed, that the combination of kerosene and electric lamps was able to increase the total catch.

Keywords : Fishing operation, kerosene and electric lamps, lift net, light illumination

\section{Pengantar}

Usaha penangkapan ikan dengan bagan apung (lift nets) mempunyai manfaat yang besar untuk perikanan skala kecil. Perkembangan perikanan bagan apung cukup bagus di Indonesia, terutama dilihat dari segi produksi dan upaya tangkap.

Menurut Flores dan Shibata (1988), unit penangkapan ikan yang termasuk jenis jaring angkat ini, di Indonesia masih bersifat tradisional dan berskala kecil. Nelayan-nelayan di Pelabuhan Ratu mengoperasikan bagan apung pada malam hari dengan menggunakan alat bantu pengumpul ikan, yaitu cahaya lampu petromaks. Kegiatan penangkapan ikan dengan menggunakan cahaya, termasuk pada bagan apung, di negaranegara yang perikanannya maju sudah dilakukan dengan tehnik yang lebih baik. Nomura dan Yamazaki (1975) mengemukakan, bahwa di Jepang perikanan dengan cahaya sudah menggunakan sumber cahaya lampu listrik putih, lampu pijar dan lampu merkuri sejak tahun 1950.

Prinsip penangkapan ikan dengan cahaya adalah memanfaatkan tingkah laku ikan yang tertarik atau menyenangi cahaya. Menurut Hela dan Laevastu (1962) ikan dapat bersifat fototaksis positif dan fototaksis negatif, yaitu memberikan reaksi terhadap cahaya. Banyak ikanikan komersial yang tertarik terhadap cahaya buatan pada malam hari dan sifat

\footnotetext{
") Dosen dan Peneliti pada Laboratorium Perikanan Fakultas Perikanan Universitas Bengkulu,

Jl. Raya Kandang Limun, Bengkulu
} 
ini banyak dimanfaatkan dalam praktek penangkapan ikan.

Ayodhyoa (1981) berpendapat, bahwa peristiwa berkumpulnya ikan di bawah cahaya dapat disebabkan peristiwa langsung, yaitu ikan-ikan tertarik oleh cahaya lalu berkumpul, dan peristiwa tidak langsung, yaitu karena ada cahaya, maka plankton, ikan-ikan kecil dan lainlain berkumpul, sehingga ikan yang lebih besar datang dengan tujuan mencari makanan. Menurut Verheyen (1964), tertariknya beberapa jenis ikan pada cahaya disebabkan oleh beberapa hal, antara lain mencari intensitas cahaya optimum, investigatory reflex, mencari makan dan bergerombol.

Penangkapan ikan dengan bagan di Indonesia, menggunakan lampu petromaks yang berkekuatan 250-400 lilin sebagai attraktor, yang digantung di atas permukaan perairan dengan jarak $1 \mathrm{~m}$ (Subani, 1972). Lampu listrik juga sudah banyak digunakan dalam penangkapan ikan (Nomura, 1985). Berbagai jenis lampu listrik, seperti lampu pijar, lampu berpendar (neon dan TL) dan lampu merkuri banyak digunakan dalam operasi penangkapan ikan, tetapi lampu pijar lebih popular dibandingkan jenis lampu lainnya.

Ikan diketahui memberi reaksi terhadap rangsangan cahaya antara 0,1 dan 0,001 lux, tergantung pada adaptasi sebelumnya terhadap cahaya atau kegelapan (Hela dan Laevastu, 1962). Ben-Yami (1980) mengemukakan, bahwa penggunaan cahaya untuk periode 30 menit sampai 3 jam cukup untuk menarik kumpulan ikan dan lampu 300 watt cukup untuk mempertahankan kelompok ikan. Selanjutnya Blaxter (1980) menjelaskan, bahwa ambang cahaya yang diperlukan ikan-ikan teleostei untuk makan adalah 0,1 lux.

Sebagian besar ikan yang tertangkap dengan cahaya adalah ikan-ikan pelagis dan tiga kelompok yang penting adalah ikan pelagis dari jenis herring dan anchovies, kelompok cumi-cumi dan saury, sedangkan jenis lainnya adalah mackerel yang berukuran kecil (BenYami, 1988).

Menurut Baskoro (1999), di Indonesia bagan dioperasikan untuk menangkap berbagai spesies ikan-ikan pelagis kecil seperti Stolephorus heterolobus, Sardinella gibbon, Leiognathus splendens, Dussumieris acuta, Gazza minuta dan Loligo edulis. Subani (1972) menambahkan, bahwa selain jenis tersebut juga tertangkap ikan kerong-kerong (Therapon theraps), gulamah (Johnius dussumieri) dan biji nangka (Upeneus sulphureus).

Uji coba penangkapan ikan dengan bagan apung yang memanfaatkan sumber cahaya lampu listrik, sebagai alternatif lain dari penggunaan sumber cahaya lampu petromaks diharapkan dapat meningkatkan hasil tangkapan.

\section{Bahan dan Metode}

Penelitian ini dilakukan di perairan Teluk Pelabuhan Ratu, Kabupaten Sukabumi, Jawa Barat. Percobaan penangkapan ikan dengan bagan apung tradisional menggunakan alat Bantu cahaya lampu petromaks dan gabungan antara lampu petromaks dengan lampu listrik. Operasi penangkapan ikan dilakukan secara bergantian antara sumber cahaya yang berbeda.

Lampu petromaks yang digunakan berjumlah 4 buah, dipasang dengan menggantungkannya ditengah-tengah bangunan bagan, kira-kira 1 meter di atas permukaan air, sedangkan lampu listrik yang digunakan adalah lampu neon bulat berkekuatan 16 watt, dipasang pada setiap sudut bagan.

Uji coba penangkapan ikan dilakukan mulai jam 18.00 (sore) sampai jam 06.00 (pagi hari) atau selama 12 jam. Setiap operasi penangkapan ikan rata-rata 2 jam, dan dalam satu malam ada 6 kali operasi penangkapan ikan. Selama 5 malam, masing-masing ada 15 kali operasi penangkapan secara bergantian 
antara penggunaan sumber cahaya yang berbeda.

Iluminasi cahaya, suhu dan salinitas perairan diukur setelah selesai penurunan (setting) waring (jaring) bagan. Iluminasi cahaya diukur dengan marine lux meter, diatas dan di bawah permukaan air pada 3 titik, yaitu pusat, tengah dan sudut bagan, untuk setiap pertambahan kedalaman 1 meter. Suhu dan salinitas diukur dengan salinity temperature bridge, masing-masing pada kedalaman $0,5,10$ dan 15 meter.

Jenis-jenis ikan yang tertangkap dicatat, dan diukur berat total serta panjang mutlak pada saat selesai pengangkatan (hauling) waring, Berat dan panjang mutlak diukur dengan metode sampling secara acak.

Untuk mengetahui perbedaan berat total dan komposisi jenis ikan yang tertangkap, dilakukan uji statistik menggunakan uji-t. Sebelum dilakukan uji statistik, terhadap data hasil tangkapan terlebih dahulu dilakukan uji kenormalan data dengan Uji Kenormalan Liliefors (Nasoetion dan Barizi, 1983). Jika data menyebar normal, dipakai analisis statistik parametric, dan sebaliknya dipakai uji statistik nonparametrik.

\section{Hasil dan Pembahasan}

Uji coba penangkapan ikan dilakukan di daerah penangkapan yang terletak pada posisi geografis $07^{0} 00^{\prime} 14,6^{\prime \prime}$ LS dan $106^{\circ}$ 31' 56,7" BT.

Hasil pengukuran data iluminnasi cahaya terhadap masing-masing perlakuan sumber cahaya yang digunakan dapat dilihat pada Tabel 1 dan Tabel 2.

Table 1. Iluminasi cahaya dari 4 buah lampu petromaks

\begin{tabular}{|c|c|c|c|}
\hline $\begin{array}{c}\text { Kedalaman } \\
(\mathrm{m})\end{array}$ & $\begin{array}{c}\text { Pusat bagan } \\
(\mathrm{Ix})\end{array}$ & $\begin{array}{c}\text { Pertengahan antara pusat dan sudut } \\
\text { bagan (Ix) }\end{array}$ & $\begin{array}{c}\text { Sudut bagan } \\
(\mathrm{Ix})\end{array}$ \\
\hline 0 & 70,0 & 6,0 & 3,0 \\
1 & 60,0 & 5,0 & 2,0 \\
2 & 25,0 & 4,5 & 1,5 \\
3 & 7,0 & 4,0 & 1,5 \\
4 & 4,0 & 3,0 & 1,0 \\
5 & 3,0 & 2,0 & 1,0 \\
6 & 2,5 & 1,0 & 0,5 \\
7 & 1,5 & 1,0 & 0 \\
8 & 1,0 & 0,5 & \\
9 & 0,5 & 0 & \\
\hline
\end{tabular}

Table 2. lluminasi cahaya dari gabungan antara 4 buah lampu petromaks dan 4 buah lampu listrik

\begin{tabular}{|c|c|c|c|}
\hline $\begin{array}{c}\text { Kedalaman } \\
(\mathrm{m})\end{array}$ & $\begin{array}{c}\text { Pusat bagan } \\
(\mathrm{x})\end{array}$ & $\begin{array}{c}\text { Pertengahan antara pusat dan sudut } \\
\text { bagan }(\mathrm{Ix})\end{array}$ & $\begin{array}{c}\text { Sudut bagan } \\
(\mathrm{Ix})\end{array}$ \\
\hline 0 & 140,0 & 6,0 & 1,0 \\
1 & 80,0 & 9,5 & 1,0 \\
2 & 40,0 & 9,0 & 1,5 \\
3 & 30,0 & 10,5 & 2,0 \\
4 & 20,0 & 8,0 & 2,5 \\
5 & 15,0 & 5,5 & 2,5 \\
6 & 10,0 & 4,0 & 2,0 \\
7 & 5,0 & 3,0 & 2,0 \\
8 & 2,0 & 2,5 & 1,5 \\
9 & 1,0 & 1,5 & 1,5 \\
10 & 0,5 & 1,0 & 1,0 \\
11 & 0,5 & 0,5 & 1,0 \\
12 & 0 & 0 & 1,0 \\
13 & 0 & 0 & 0 \\
\hline
\end{tabular}


Penurunan iluminasi cahaya terjadi secara tidak teratur. Hal ini sesuai dengan pernyataan Spanis (1982), bahwa intensitas cahaya akan berkurang dengan derajat yang bervariasi dalam kolom air, tergantung pada jumlah penyerapan material terlarut.

Pada penggunaan lampu petromaks, penetrasi cahaya mencapai kedalaman maksimum $9 \mathrm{~m}$ (pusat bagan), $8 \mathrm{~m}$ (pertengahan antara pusat dan sudut bagan), dan $6 \mathrm{~m}$ (sudut bagan). Untuk kombinasi lampu petromaks dengan lampu listrik, penetrasi cahaya mencapai kedalaman maksimum $11 \mathrm{~m}$ (pusat bagan dan pertengahan antara pusat dan sudut bagan), dan $12 \mathrm{~m}$ (sudut bagan). Perbedaan ini disebabkan oleh intensitas cahaya tambahan dari lampu listrik. Penetrasi cahaya lebih dalam pada sudut bagan, karena penerangan lampu listrik yang dipasang pada setiap sudut bagan.

Jenis ikan yang tertangkap secara keseluruhan pada uji coba penangkapan dengan bantuan cahaya adalah 18 jenis. Sebanyak 17 jenis diantaranya merupakan ikan-ikan pelagis kecil yang fototaksis positif, sedangkan satu jenis lainnya adalah ikan layur (Trichiurus savala) yang merupakan jenis ikan dasar (demersal).
Tertangkapnya ikan layur disebabkan oleh aktivitas ikan tersebut mencari makan, bukan tertarik oleh cahaya secara langsung. Sebagaimana pernyataan Ayodhyoa (1981), bahwa peristiwa berkumpulnya ikan dibawah sumber cahaya dapat terjadi secara langsung karena tertarik cahaya, dan tidak langsung karena datang untuk memakan ikan-ikan kecil.

Komposisi hasil tangkapan ikan selama uji coba penangkapan ikan dengan menggunakan bantuan cahaya lampu petromaks dan lampu listrik dapat dilihat pada Tabel 3 dan Tabel 4 berikut ini.

Pada uji coba penangkapan ikan menggunakan bantuan cahaya lampu petromaks, tertangkap 12 jenis ikan, 9.084 ekor dengan berat total $85,12 \mathrm{~kg}$, sedangkan pada penangkapan dengan menggunakan kombinasi lampu petromaks dan lampu listrik, tertangkap 18 jenis ikan, 12.695 ekor dan berat total $148,67 \mathrm{~kg}$. Jenis ikan yang dominan tertangkap, untuk kedua perlakuan adalah sama, yaitu ikan layang, cumi-cumi dan ikan tembang. Ketiga jenis ikan tersebut tergolong kelompok ikan fototaksis positif.

Tabel 3. Komposisi hasil tangkapan bagan apung menggunakan lampu petromaks

\begin{tabular}{|c|c|c|c|c|c|}
\hline No. & $\begin{array}{l}\text { Jenis Ikan Yang } \\
\text { Tertangkap }\end{array}$ & $\begin{array}{c}\text { Jumlah } \\
\text { (ekor) }\end{array}$ & $\begin{array}{l}\text { Berat } \\
(\mathrm{kg})\end{array}$ & $\begin{array}{l}\text { Panjang rata- } \\
\text { rata }(\mathrm{cm})\end{array}$ & $\begin{array}{l}\text { Frekwensi tertangkap } \\
\text { (kali)* }^{*}\end{array}$ \\
\hline 1 & Daun bambu & 208 & 1,8 & 7,7 & 3 \\
\hline 2 & Cumi-cumi/Loligo sp & 2897 & 31,43 & 5,3 & 14 \\
\hline 3 & Rebon & - & 1,2 & - & 1 \\
\hline 4 & Layang & 3813 & 18,8 & 7,9 & 9 \\
\hline 5 & Tembang & 1467 & 12,8 & 9,4 & 5 \\
\hline 6 & Layur & 13 & 1,25 & 42,7 & 3 \\
\hline 7 & Belang kecembang & 262 & 2,11 & 7,2 & 4 \\
\hline 8 & Kembung & 21 & 0,3 & 8,1 & 1 \\
\hline 9 & Kerong-kerong & 15 & 3,0 & 16,8 & 1 \\
\hline 10 & Senangin & 139 & 5,8 & 6,4 & 2 \\
\hline 11 & Selayang & 224 & 6,43 & 9,9 & 5 \\
\hline 12 & Selar & 27 & 0,2 & 8,4 & 1 \\
\hline \multicolumn{2}{|r|}{ Jumlah } & 9086 & 85,12 & & \\
\hline
\end{tabular}

* Dari 15 kali operasi penangkapan 
Tabel 4. Komposisi hasil tangkapan dengan ikan bagan apung menggunakan gabungan lampu petromaks dan lampu listrik

\begin{tabular}{|c|c|c|c|c|c|}
\hline No. & Jenis Ikan Yang Tertangkap & $\begin{array}{c}\text { Jumlah } \\
\text { (ekor) }\end{array}$ & $\begin{array}{l}\text { Berat } \\
(\mathrm{kg})\end{array}$ & $\begin{array}{l}\text { Panjang rata-rata } \\
(\mathrm{cm})\end{array}$ & $\begin{array}{c}\text { Frekwensi tertangkap } \\
\left(\text { kali }^{*}\right.\end{array}$ \\
\hline 1 & Daun bambu & 108 & 1,07 & 8,7 & 3 \\
\hline 2 & Cumi-cumi & 4563 & 34,86 & 6,2 & 15 \\
\hline 3 & Rebon & & 2,0 & 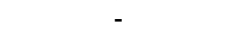 & 2 \\
\hline 4 & Layang & 4485 & 47,66 & 7,78 & 9 \\
\hline 5 & Tembang & 2127 & 15,4 & 8,26 & 4 \\
\hline 6 & Layur & 172 & 23,22 & 52,78 & 10 \\
\hline 7 & Belang kecembang & 873 & 8,3 & 9,46 & 6 \\
\hline 8 & Kembung & 146 & 2,3 & 8,38 & 3 \\
\hline 9 & Kerong-kerong & 50 & 10,0 & 15,75 & 1 \\
\hline 10 & Senangin & 166 & 7,9 & 6,35 & 3 \\
\hline 11 & Selayang & 170 & 6,80 & 8,0 & 4 \\
\hline 12 & Selar & 53 & 0,5 & 7,8 & 2 \\
\hline 13 & Gelang sadap & 18 & 3,6 & 19,9 & 1 \\
\hline 14 & Pepetek & 33 & 0,5 & 5,95 & 1 \\
\hline 15 & Kue & 12 & 0,7 & 8,6 & 1 \\
\hline 16 & Tatengkek & 27 & 0,95 & 8,8 & 2 \\
\hline 17 & Ekor kuning & 1 & 0,06 & 6,5 & 1 \\
\hline 18 & Sepah & 59 & 0,8 & 6,6 & 1 \\
\hline \multicolumn{2}{|r|}{ Jumlah } & 12685 & 148,67 & & \\
\hline
\end{tabular}

* Dari 15 kali operasi penangkapan

Menurut Nomura (1985), jenis ikan yang sangat tertarik pada cahaya lampu salah satunya adalah cumi-cumi. Buchsbaum et al., (1987), menjelaskan bahwa tertariknya cumi-cumi terhadap cahaya karena memiliki perkembangan mata yang sempurna sehingga sensitif terhadap cahaya. Barnes (1987) menambahkan bahwa hewan yang termasuk cephalopoda bergerak naik ke atas selama malam hari.

Sensitivitas cumi-cumi yang tinggi terhadap cahaya juga dapat dilihat dari frekuensi tertangkapnya sebanyak 14 kali dari 15 kali operasi penangkapan dengan lampu petromak dan tertangkap setiap kali operasi penangkapan pada penggunaan lampu petromaks yang digabung dengan lampu listrik.

Berdasarkan jam operasi penangkapan ikan, jumlah jenis dan berat ikan yang paling banyak tertangkap, terjadi antara jam 20.00-24.00 untuk kedua perlakuan. Fenomena ini didukung oleh pendapat Gunarso (1985), bahwa penangkapan ikan dengan lampu akan lebih efektif sebelum tengah malam, karena fototaksis yang maksimum ikan terdapat pada waktu tersebut.
Pada operasi penangkapan ikan dengan bantuan lampu petromaks, jumlah hasil tangkapan terbanyak terjadi pada suhu rata-rata $23,4^{\circ} \mathrm{C}$ dan salinitas rata-rata 33,11 o/oo (jam 24.00), sedangkan pada operasi penangkapan dengan bantuan sumber cahaya gabungan lampu petromaks dan lampu listrik, hasil tangkapan terbanyak adalah pada suhu rata-rata $23,2^{\circ} \mathrm{C}$ dan salinitas rata-rata 31,21 o/oo (jam 20.00). Banyaknya ikan yang tertangkap pada operasi penang-kapan ikan pada suhu rata-rata $23,4^{\circ} \mathrm{C}$ dan $23,2^{\circ} \mathrm{C}$ lebih disebabkan ikan mendapatkan kondisi yang sesuai untuk aktivitasnya. Sebagaimana yang dikemukakan Hela dan Laevastu (1970), ikan akan mencari daerah yang paling menyenangkan hidupnya pada suatu lingkungan yang dipengaruhi oleh faktor fisik dan keadaan biologi, dan hampir semua stok ikan memiliki suhu optimum.

Kisaran salinitas rata-rata dimana ikan banyak tertangkap(31,21 0/00-33,11 0/00) menunjukkan kondisi optimal untuk ikan. Dari segi penangkapan ikan, salinitas suatu perairan tidak mempunyai pengaruh yang besar terhadap keberadaan ikan. Menurut Sumich (1984), salinitas lebih berpengaruh terhadap proses metabolisme ikan secara individu. 
Hasil uji statistik (uji-t) terhadap jumlah berat total ikan yang tertangkap, menunjukkan bahwa nilai t hitung adalah 2,103 sedangkan nilai t table pada taraf $\alpha=0,05$ adalah 2,042. Nilai t hitung yang lebih besar dari t tabel menunjukkan adanya perbedaan nyata jumlah berat total ikan yang tertangkap antara penggunaan sumber cahaya lampu petromaks, dengan kombinasi lampu petromaks dan lampu listrik. Hasil uji statistik terhadap komposisi jenis ikan yang tertangkap, diperoleh nilai t hitung adalah 2,640 lebih besar dari $\mathrm{t}$ table pada taraf $\alpha=0,05$ yaitu 2,042. Dengan demikian komposisi jenis ikan yang tertangkap juga berbeda nyata antara penggunaan sumber cahaya lampu petromaks, dengan kombinasi lampu petromaks dan lampu listrik.

Kombinasi lampu petromaks dan lampu listrik memberikan hasil yang lebih baik. Hal ini disebabkan adanya perbedaan intensitas sumber cahaya, dimana kombinasi lampu petromaks dan lampu listrik memberikan intensitas cahaya yang lebih besar, sehingga penetrasi cahaya keperairan lebih dalam. Selain itu juga disebabkan pemasangan lampu listrik pada sudut bagan, sehingga radius pengaruh cahaya lebih luas dibandingkan penggunaan lampu petromaks yang dipasang di pusat bagan.

Nikonorov (1975) menjelaskan bahwa radius tertariknya ikan tergantung pada besarnya kekuatan penyinaran sumber cahaya, dan pada kasus terakhir, peningkatan kuat penyinaran disertai peningkatan kekuatan penerangan. Selanjutnya, peningkatan intensitas penyinaran lampu, secara simultan menyebabkan peningkatan jumlah ikan yang ada dalam zone cahaya, tetapi tidak selalu mengakibatkan peningkatan hasil tangkapan, sebab dalam kasus ini ikan tetap menjaga jarak dari sumber cahaya dan efektivitas penangkapan ditentukan oleh dimensi alat penangkapan ikan.

Nomura (1985) menambahkan, cahaya yang menyebar di atas area yang luas biasanya mempunyai iluminasi tidak dalam, karena itu cahaya bermanfaat untuk memikat ikan dalam lingkungan yang luas tapi dangkal.

\section{Kesimpulan dan Saran}

\section{Kesimpulan}

Penggunaan sumber cahaya kombinasi antara lampu petromaks dan lampu listrik memberikan berat total dan komposisi jenis hasil tangkapan yang lebih tinggi dibandingkan penggunaan sumber cahaya lampu petromaks saja.

Hasil tangkapan yang lebih baik pada penggunaan sumber cahaya kombinasi antara lampu petromaks dan lampu listrik disebabkan intensitas cahaya yang lebih besar dan radius pencahayaan yang lebih luas.

\section{Saran}

Perlu penelitian lanjutan untuk dimensi waktu yang berbeda dan penggunaan lampu listrik dengan daya (watt) yang lebih besar dan jenis lampu yang berbeda.

\section{Ucapan terima kasih}

Penulis mengucapkan terima kasih yang sebesar-besarnya kepada : Prof. Dr. Daniel R. Monintja, A.U Ayodhyoa, M.Sc, Dr. Ir. Indra Jaya, M.Sc. yang telah berkenan sebagai pembimbing penelitian, dan Dr. Ir. Mulyono S. Baskoro, M.Sc. yang membantu penulis selama pelaksanan penelitian.

\section{Daftar Pustaka}

Ayodhyoa, A.U.. 1981. Metode Penangkapan Ikan. Yayasan Dewi Sri, Bogor. $97 \mathrm{p}$.

Barnes, R.D.. 1987. Invertebrate Zoology. Saunders College Publishing. $893 \mathrm{p}$.

Baskoro, M. S.. 1999. Capture Process of the Floated Bamboo-Platform Lift Net with Light Attraction (Bagan). 
Doctoral Course of Marine Science and Technology. Tokyo University of Fisheries. $128 \mathrm{p}$.

Ben-Yami, M.. 1976. Fishing With Light. FAO of the United Nations by Fishing News Books, Ltd. Long Garden Walk, Farnham, England. $150 \mathrm{p}$.

1980. Tuna Fishing with Pole and Line. FAO of the United Nations by Fishing News Books, Ltd. Long Garden Walk, Farnham, England. 150 p.

1988. Tuna Fishing with Pole and Line. FAO of the United Nations by Fishing News Books, Ltd. Long Garden Walk, Farnham, England. 150 p.

1988. Attracting Fish With Light. FAO Training Series 14. FAO of the United Nations, Rome. $72 \mathrm{p}$.

Blaxter, J.H.S.. 1980. Vision and the Feeding of Fishes. P. 32-56. In : ICLARM Conference Proceedings 5, Manila.

Buchsbaum, R.M., M. Buchsbaum, J. Pearse and V. Pearse. 1987. Animal Without Backbones. Third Editon. The University of Chicago. 527 p.

Flores, E and K. Shibata. 1988. Survey of Small-Scale Fishing Gears in Selected Areas of Indonesia and Phillipines. P. 221-226. In : World Symposium on Fishing Gear and Fishing Vessel Design. Marine Institute St. John's New Foundland, Canada.

Gunarso, W.. 1985. Tingkah laku ikan dalam hubungannya dengan alat, metode dan taktik penangkapan. Fakultas Perikanan, IPB Bogor. $149 \mathrm{p}$.
Hela, I and T. Laevastu. 1962. Fisheries Hydrography. Fishing News (Books) Ltd. London. 137 p.

---------. 1970. Fisheries Oceanography. Fishing News (Books) Ltd. London. 206 p.

Nasution, A.H. dan Barizi. 1983. Metode Statistika untuk Penarikan Kesimpulan. Penerbit Gramedia, Jakarta. 223 hal.

Nikonorov, I.V..1975. Efficiency of the Light Source in Fishing with Light. P. 63-111. In : Interaction of Fishing Gear with Fish Aggregations. Israel Program for Scientific Translations, Jerusalem.

Nomura, M. and T. Yamazaki. 1975. Fishing Tehniques. JICA, Tokyo. $206 \mathrm{p}$.

Nomura, M.. 1985. Fishing Tehniques 3. Kanagawa International Fisheries Training, JICA. Tokyo. 108 p.

Nontji, A.. 1987. Laut Nusantara. Penerbit Djambatan, Jakarta. 367 hal.

Spanis, J.D.. 1982. Basic Micro Computer Models in Biology. Addison-Wesley Publishing Company, Massachusetts. $354 \mathrm{p}$.

Subani, W.. 1972. Alat dan Cara Penangkapan Ikan di Indonesia. Jilid I. LPPL, Jakarta.

Sumich, J.L.. 1984. An Introduction to Biology of Marine Life. Third Edition. Wm C. Brown Publisher. Dubuque, lowa. $386 \mathrm{p}$.

Verheyen, F.J.. 1964. Attraction of Fish by the Use of Light. P. 548-549. In : Modern Fishing Gear of the World. Fishing News (Books) Ltd London. 